\title{
Comparative Study of the Catalytic Oxidation of Hydrocarbons on Platinum and Palladium Wires and Nanoparticles
}

Mohamed N. Marei ${ }^{\mathrm{a}, \mathrm{b},{ }^{*}, \text { Hassnain A. Khan }}{ }^{\mathrm{c}}$, Jihad A. Badra ${ }^{\mathrm{d}}$, Alejandro Montoya ${ }^{\mathrm{e}}$, Aamir Farooq ${ }^{\mathrm{c}}$, and Assaad R. Masri ${ }^{\mathrm{a}, \text { * }}$

${ }^{a}$ School of Aerospace, Mechanical and Mechatronic Engineering, The University of Sydney, New South Wales 2006, Australia

${ }^{\mathrm{b}}$ Mechanical Engineering Department, Faculty of Engineering, Alexandria University, Alexandria 21544, Egypt

c Clean Combustion Research Centre, King Abdullah University of Science and Technology (KAUST), Physical Sciences and Engineering Division, Thuwal 23955, Saudi Arabia

d Transport Technologies Division, R\&DC, Saudi Aramco, Dhahran 31311, Saudi Arabia

e School of Chemical and Biomolecular Engineering, The University of Sydney, New South Wales 2006, Australia

\section{Supporting Information}

\section{Optimisation of mixing region in the wire reactor}

A 3D Ansys fluent model was created to simulate the mixing process between the air and hydrocarbons, in order to optimise the mixing stage design. The $\mathrm{O}_{2}$ mass fraction used to trace the mixing quality. Figure S1 (a) shows the simulation of mixing between air and fuel taking place in the mixing section, specified in Figure 1, and how $\mathrm{O}_{2}$ is fully distributed across the outlet plane before entering the reactor section. This gives is an indication of the high mixing quality. Mixing quality was also checked experimentally by measuring the temperature profile at the outlet after the hot air stream was fully mixed with the cold fuel stream with different mixing ratios. Temperature profile is shown in Figure S1 (b). 

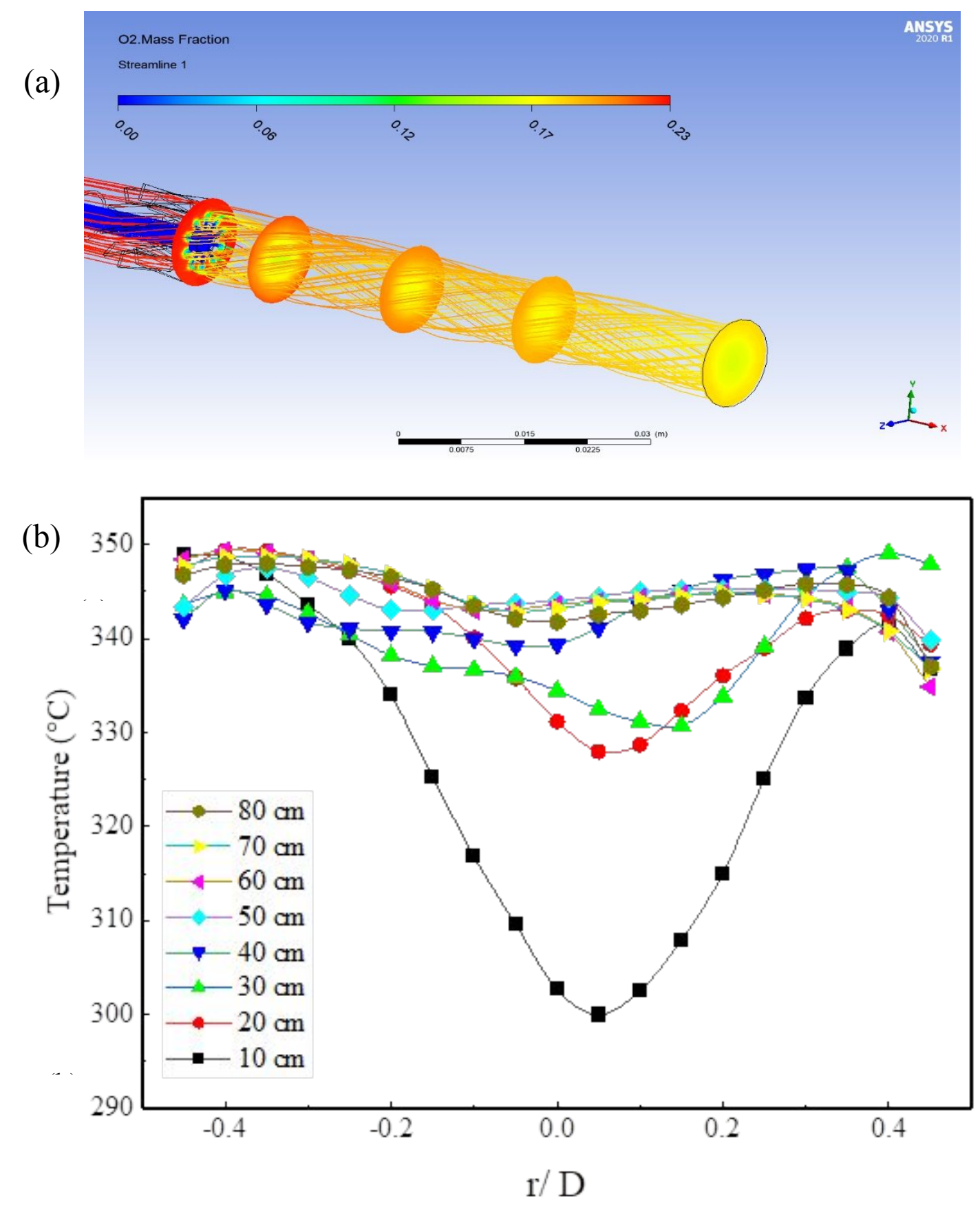

Figure S1 (a) The $\mathrm{O}_{2}$ mass fraction simulated numerically. (b) Experimental temperature measurements at the end of the mixing region while varying the mixing length. 


\section{$\underline{\text { Experimental setup of nanoparticles reactor }}$}

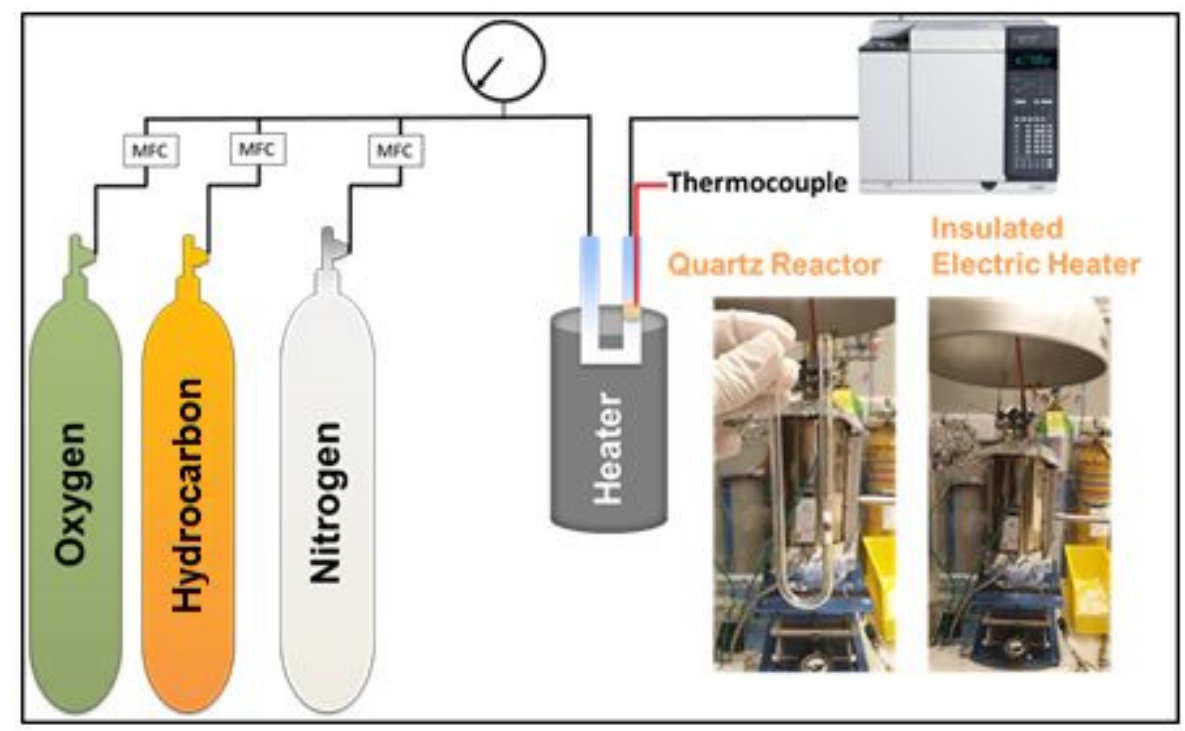

Figure S2 Schematic of the experimental setup for the nanoparticles catalytic reactor for hydrocarbon oxidation using the nano powdered catalyst.

\section{BET Test Conditions:}

The specific surface area and average pore diameter were analysed by $\mathrm{N}_{2}$ static adsorptiondesorption at $-196{ }^{\circ} \mathrm{C}$ with Micromeritics ASAP-2020 instrument. All as-prepared catalysts were first degassed at $80^{\circ} \mathrm{C}$ for $12 \mathrm{~h}$. The specific surface area was determined by means of Brunauer-Emmett-Teller (BET) in a relative pressure range of 0.05-0.3 with the assumption that the cross-sectional area of $\mathrm{N}_{2}$ is $0.162 \mathrm{~nm}^{2}$. The pore size distributions and pore volumes were calculated from the adsorption branches by Barrett-Joyner-Halenda (BJH) methods. 


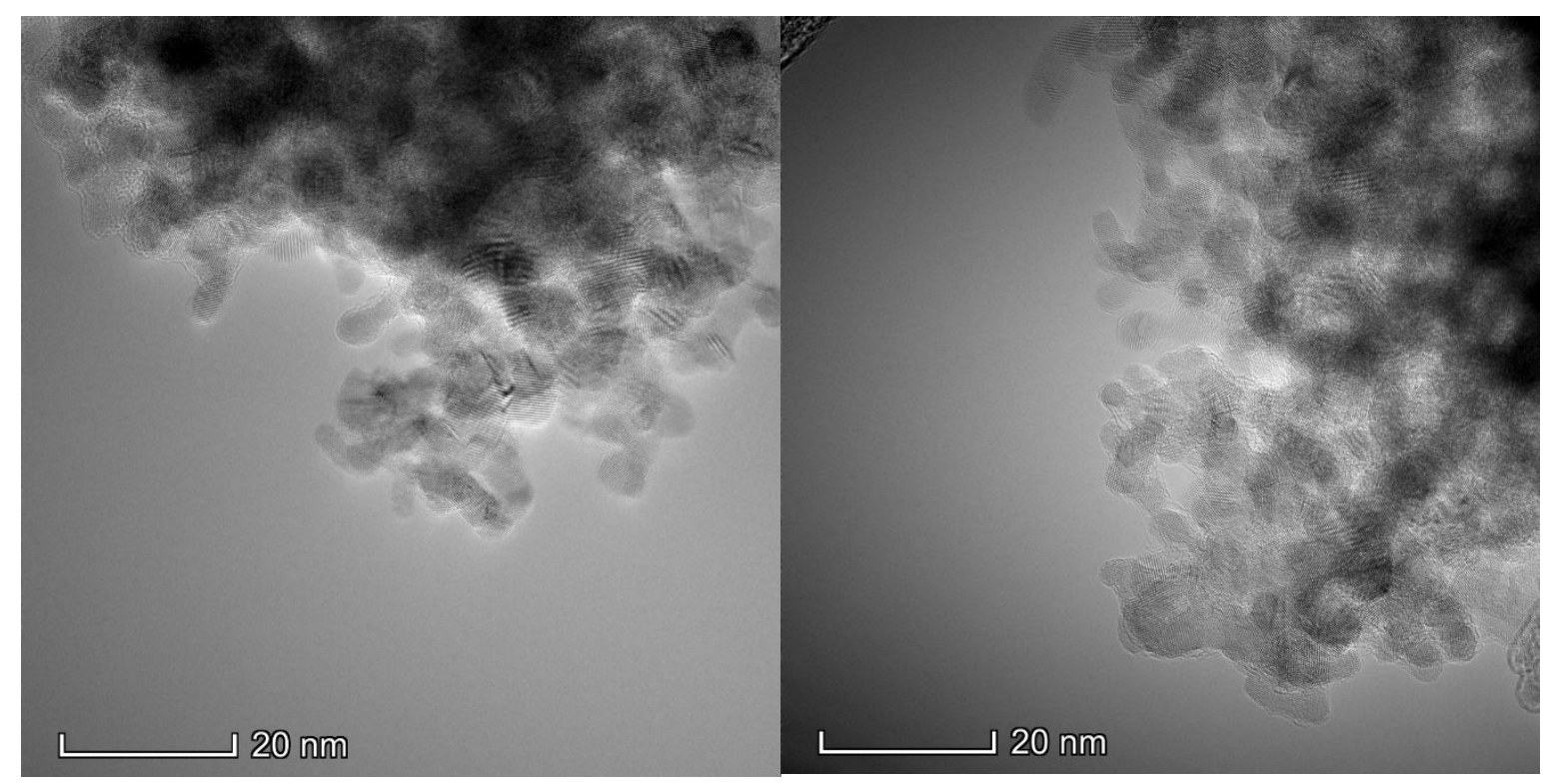

Figure S3 TEM Images of Pd Nanoparticles.
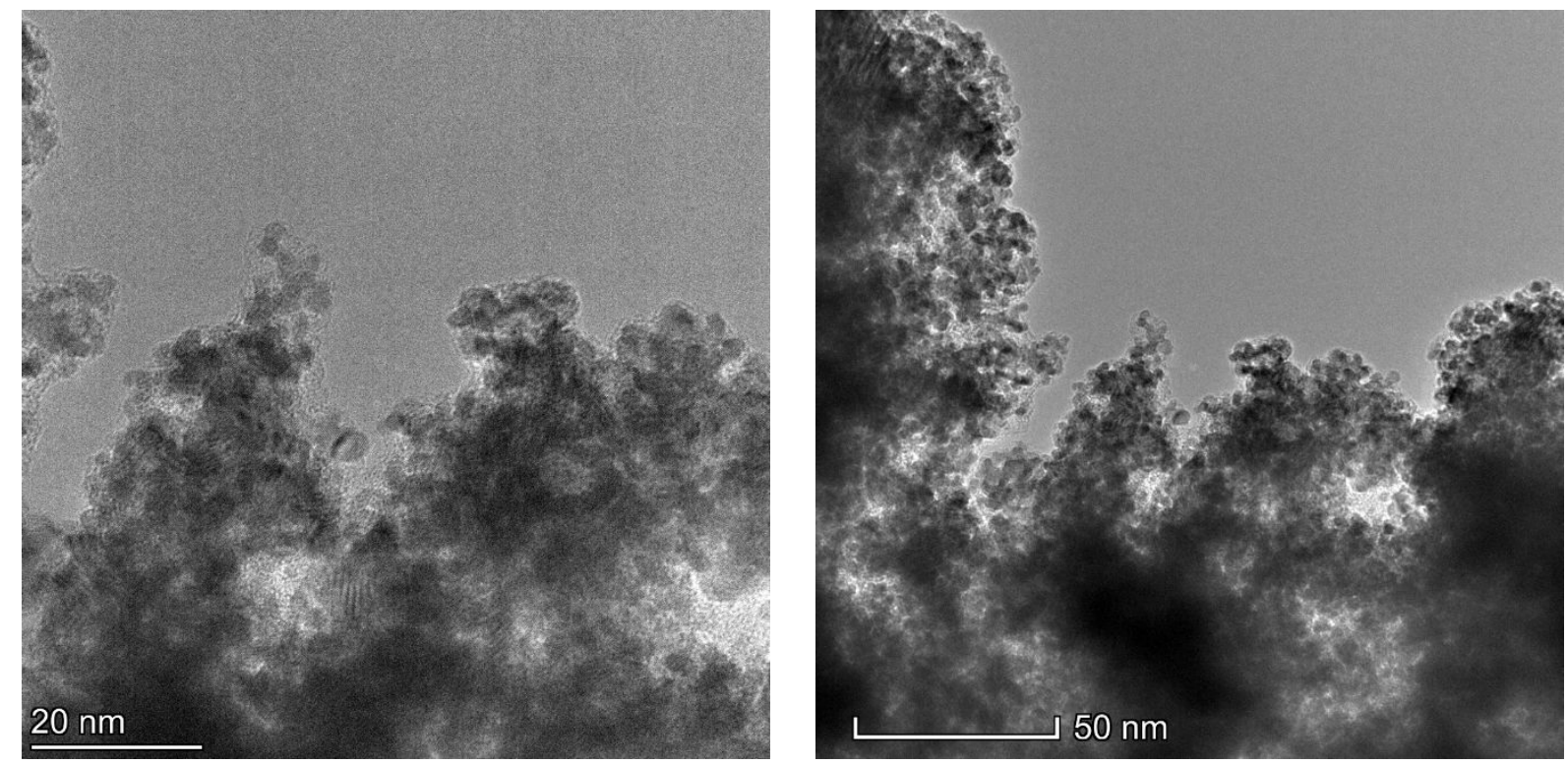

Figure S4 TEM Images of Pt Nanoparticles.

\section{$\underline{\text { Micro-GC and GC operational conditions }}$}

Table S1 Specific operation conditions for micro-GC used to analyse products from wire reactor.

\begin{tabular}{|l|l|l|}
\hline Condition & Molsieve 5A column & PoraPLOT Q column \\
\hline Run time (sec.) & 205 & 205 \\
\hline
\end{tabular}




\begin{tabular}{|l|l|l|}
\hline Injection time $(\mathrm{sec})$. & 30 & 30 \\
\hline Injection temperature $\left({ }^{\circ} \mathrm{C}\right)$ & 110 & 110 \\
\hline Oven temperature $\left({ }^{\circ} \mathrm{C}\right)$ & 120 & 65 \\
\hline Column pressure $(\mathrm{KPa})$ & 200 & 200 \\
\hline Gases analysed & $\mathrm{H}_{2}, \mathrm{O}_{2}, \mathrm{~N}_{2}, \mathrm{CH}_{4}$, and $\mathrm{CO}$ & $\begin{array}{l}\mathrm{CH}_{4}, \mathrm{CO}_{2}, \mathrm{C}_{2} \mathrm{H}_{4}, \mathrm{C}_{2} \mathrm{H}_{6} \text {, and } \\
\mathrm{C}_{3} \mathrm{H}_{6}\end{array}$ \\
\hline
\end{tabular}

Operational parameters for GC connected to the nanoparticles reactor

The GC used is Agilent 7890B, equipped with a split less injector TCD, FID and two 6way valves enclosed in a heating oven and electric flow controllers controlling all the gas flows. The GC was controlled and automated by the Agilent online workstation. Ultrahigh purity Helium 99.999\% carrier gas was passed through purifier filter before entering the GC. Hydrogen was directly from hydrogen generator and zero-gas air were used to generate the FID flame. The GC is equipped with three columns; 3Ft 1/8 2mm HayeSep Q 80/100 Inner Diameter: 2mm, Length: 0.9m, 10' Molesieves and HP-PLOT AL2O3 'S'. The temperature of the oven-containing columns was ramped from $60{ }^{\circ} \mathrm{C}$ to $180{ }^{\circ} \mathrm{C}$ with ramp rate of $40{ }^{\circ} \mathrm{C} / \mathrm{min}$. The column temperature was hold for $5 \mathrm{~min}$ at $180{ }^{\circ} \mathrm{C}$ that builds total analysis time of 8.0 minutes.

The product gas stream exiting the reactor are injected into the GC. The sample passed through the decision valve having sample loop of volume $250 \mu$ and entered the HP-PLOT $\mathrm{AL}_{2} \mathrm{O}_{3}$ ' $\mathrm{S}$ ' column that was held at $60{ }^{\circ} \mathrm{C}$ and light hydrocarbon species adsorbed onto the column, while the other gases like $\mathrm{CO}_{2}$, moisture, $\mathrm{O}_{2}$ and nitrogen gaseous species continued, unresolved, to the HayeSep Q and Molesieves column. The FID signals for methane and ethylene appears at 1.45 and 1.6 min respectively. The signal for $\mathrm{CO}_{2}$ appears at $1.9 \mathrm{~min}$ in TCD signals window. 